\title{
Barreras en los procesos de Educación Inclusiva dirigidos a niños con Trastorno del Espectro Autista (TEA)
}

Estudio cualitativo con docentes de una institución educativa

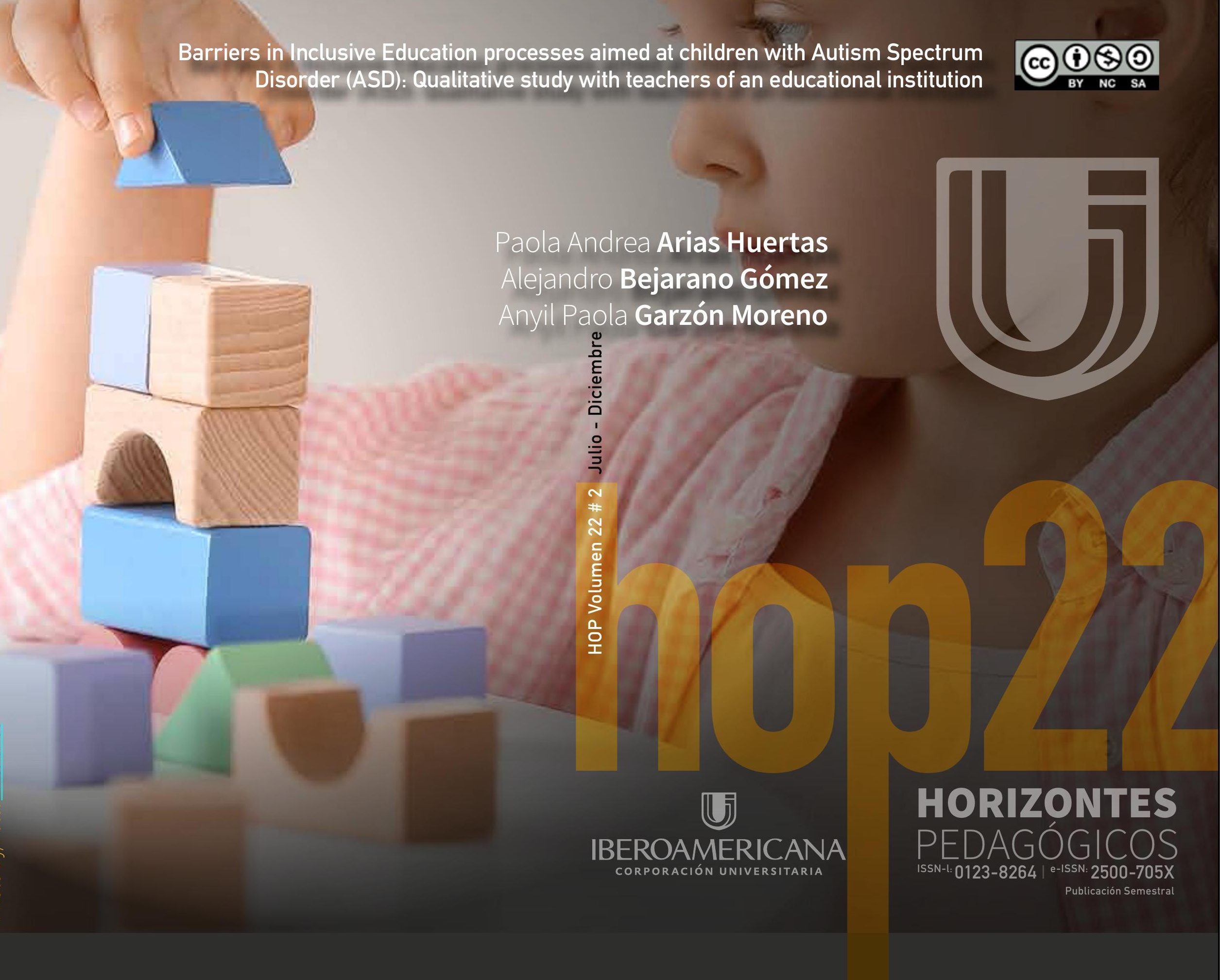


Barriers in Inclusive Education processes aimed at children with Autism Spectrum Disorder (ASD)

Subtitle: Qualitative study with teachers of an educational institution

Título: $\quad$ Barreras en los procesos de Educación Inclusiva dirigidos a niños con Trastorno del Espectro Autista (TEA)

Subtítulo: Estudio cualitativo con docentes de una institución educativa

Alt Title / Título alternativo:

[en]: $\quad$ Barriers in Inclusive Education processes aimed at children with Autism Spectrum Disorder (ASD)

Author (s) / Autor (es):

Arias Huertas, Bejarano Gomez \& Garzón Moreno

Keywords / Palabras Clave:

Teachers; Caregivers; Inclusive education; Autism; Grounded theory.

[es]: Docentes; Cuidadores; Educación inclusiva; Autismo; Teoría fundamentada.

Submited: 2020-07-21

Acepted: 2020-09-02

\section{Resumen}

Objetivo: En esta investigación se buscó describir las percepciones de un grupo de docentes sobre los procesos de educación inclusiva en los que participan niños con trastorno del espectro autista

(TEA) y sobre aquellos factores que atraviesan su instanciación y desarrollo. Método: la investigación involucró 12 participantes (docentes) de una

institución educativa de la ciudad de Bogotá y se desarrolló entre los meses de mayo y octubre del año 2019. Se implementó un diseño de Teoría Fundamentada basado en la propuesta de Strauss

y Corbin (1998) que se desarrolló a través de tres etapas; en las dos primeras se aplicaron entrevistas y en la tercera se realizó un grupo focal. Resultados:

Los resultados de cada fase se analizaron

siguiendo el procedimiento de la Codificación teórica (codificación abierta, codificación axial y codificación selectiva) propuesto por Strauss

y Corbin (1998). Tras el desarrollo de las tres fases y la implementación de estrategias para garantizar calidad (p.e. auditoria por parte de

un revisor externo al proceso de recolección y triangulación entre investigadores), se logró saturar

una categoría central que emergería como un elemento común a las percepciones narradas por cada uno de los participantes: barreras que limitan los procesos de inclusión. Al dimensionalizar esta categoría emergieron 4 subcategorías. 1) Barreras asociadas a los procesos de formación profesional

para la diversidad; 2) Barreras asociadas a la participación de cuidadores en los procesos de educación inclusiva; 3) Barreras asociadas

al uso de mediaciones efectivas y estrategias pedagógicas y didácticas para su uso en el aula de clase; 4) barreras asociadas a factores normativos y socioeconómicos. Se finaliza el texto sugiriendo posibles vías y estrategias que podrían llegar a articularse en una propuesta teórico-interventiva de carácter inclusiva que pueda contribuir al fortalecimiento de los procesos de educación

inclusiva en el contexto de estudio y que sirva como guía para el desarrollo de otros procesos en otros contextos.

\section{Abstract}

Objective: This research sought to describe the perceptions of a group of teachers about the processes of inclusive education in which children with Autism Spectrum Disorder (ASD) participate and about those factors that go through their instance and development. Method: the research involved 12 participants (teachers) from an educational institution in the city of Bogotá and were affected between the months of May and October of the year 2019. A Grounded Theory design based on the proposal of Strauss and Corbin was implemented (1998) that can be

followed through three stages; interviews were applied in the first two and a focus group was carried out in the third. Results: The results of each phase will be analyzed following the procedure of Theoretical Coding (open coding, axial coding and selective coding) proposed by Strauss and Corbin (1998). After the development of the three phases and the implementation of strategies for quality assurance (auditorium by a reviewer external to the collection and triangulation process between researchers), a central category can emerge that emerges as a common element to the perceptions narrated by each of the participants: barriers that

limit the inclusion processes. When sizing this category, 4 subcategories emerged. 1) Barriers associated with professional training processes

for diversity; 2) Barriers associated with the participation of caregivers in inclusive education processes; 3) Barriers associated with the use of effective mediations and pedagogical and didactic strategies for use in the classroom; 4) barriers associated with normative and socioeconomic factors. The text ends by suggesting possible ways and strategies that can be articulated in an inclusive theoretical-intervention proposal that can contribute to the cooperation of inclusive education processes in the context of study and that serves as a guide for the development of others. processes in other contexts.
Paola Andrea Arias Huertas, Psi

Source I Filiacion:

Corporación universitaria iberoamericana

BIO

Psicologá de la Corporación Universitaria Iberoamericana.

City I Ciudad:

Bogotá DC [CO]

e-mail:

andreearias2014@gmail.com
Alejandro Bejarano Gomez, [Dr] [Msc] Psl sp ORCID: $\quad$ 0000-0003-3322-7001

Source I Filiacion

Corporación universitaria iberoamericana

BIO:

Psicólogo, candidato a Doctor en Psicología de la Universidad Nacional de Colombia. Docente Investigador Grupo de Investigación Psicología, Ciencia y Tecnología de la Corporación Universitaria Iberoamericana.

\section{City I Ciudad:}

Bogotá DC [CO
Anyil Paola Garzón Moreno, Psi Source I Filiacion:

Corporación Universitaria Iberoamericana

BIO:

Psicologá de la Corporación Universitaria Iberoamericana.

City I Ciudad:

Bogotá DC [CO 


\section{Barreras en los procesos de Educación Inclusiva dirigidos a niños con Trastorno del Espectro Autista (TEA) Estudio cualitativo con docentes de una institución educativa}

Barriers in Inclusive Education processes aimed at children with Autism Spectrum Disorder (ASD): Qualitative study with teachers of an educational institution

Paola Andrea Arias Huertas Alejandro Bejarano Gómez Anyil Paola Garzón Moreno

\section{Introducción}

El trastorno del espectro autista (TEA) comprende una serie de alteraciones que afectan la interacción social, el comportamiento y la comunicación desde los primeros años de la infancia, acompañando a la persona durante todo su ciclo vital (Frith, 2003, como se cita en Baña, 2015). El TEA es considerado como un síndrome heterogéneo (que puede evolucionar u obtener otras características) debido a la amplia diferencia de las personas que lo presentan (Cuxart, 2000). Dentro de sus síntomas se identifican alteraciones en el lenguaje, conductas inapropiadas como conductas estereotipadas, comportamientos impulsivos debido a déficits en sus habilidades sociales y que conllevan a dificultades para adaptarse y desenvolverse en diferentes contextos (Bareño, 2015; Massani, García y Hernández, 2015; Nunes y Schmidt, 2019). Este conjunto de síntomas y manifestaciones que alteran el neurodesarrollo y que se engloban bajo el término "espectro" incluye dificultades en la interacción social recíproca, el desarrollo del lenguaje, la comunicación verbal y no verbal e intereses restringidos (Correia 2013). 


\section{Barreras en los procesos de Educación Inclusiva dirigidosa niños con Trastorno delEspectro Autista(TEA)}

Estudio cualitativo con docentes de una institución educativa

las alteraciones más comunes en el Autismo se presentan: 1) a nivel del desarrollo del lenguaje, la interacción social y la comunicación; 2) en términos de patrones de comportamientos intereses y actividades restringidos y repetitivos, (APA, 2013). Este conjunto de trastornos de elevada prevalencia y heterogeneidad trae efectos importantes para el niño, la familia, y los sistemas sanitario y educativo (Klin, 2015). Para 2020 la Academia Americana de Pediatría (AAP, 2020) estima que 1 de cada 59 niños en el mundo presentará algún trastorno del espectro autista (TEA), y según lo indica esta misma entidad, el costo de vida, la educación, la salud, entre otras necesidades para una persona con TEA, puede oscilar entre los \$1.4 y \$2.4 millones de dólares.

Actualmente los centros para el control y prevención de enfermedades de los Estados Unidos (CDC) estiman la prevalencia de TEA en torno al $1 \%$ de las demás enfermedades, además, parece en todos los grupos raciales, étnicos y socioeconómicos, es 5 veces más frecuente en niños que en niñas, pero la proporción se iguala hasta 2:1 en los casos con menor cociente intelectual ( $\mathrm{Cl}$ ), más gravemente afectados. Estas cifras suponen un incremento de la frecuencia de los TEA. De hecho, según los datos consignados en el Informe General sobre Autismo (2015), en Estados Unidos, se estima que en el mundo un niño es diagnosticado con TEA cada 21 minutos, siendo este el factor que más genera aumento en los índices de discapacidad en ese país (Casas y Aparicio, 2016).

Aunque los estudios no descartan factores demográficos o ambientales responsables de un aumento de la prevalencia (p. ej., niños hijos de padres de más edad o supervivencia de niños de alto riesgo como los grandes prematuros o de muy bajo peso al nacer), la mayoría de los expertos explican este aumento de la prevalencia de los TEA como el resultado de una mayor sensibilidad y toma de conciencia de estos trastornos, así como de su mayor reconocimiento y detección (Espín, Del Valle y Espín, 2013).

Con el objetivo de afrontar las necesidades de atención inherentes a este problema de salud pública y de garantizar tratamientos efectivos e integrales y de fijar las condiciones para el otorgamiento de terapias y tratamientos seguros, eficientes, sostenibles financieramente para el sistema de salud y los usuarios, el Ministerio de Salud y Protección Social y el Instituto de Evaluación Tecnológica en Salud (IETS) de Colombia, lanzaron el Protocolo Clínico para el Diagnóstico y Tratamiento de los Niños y Niñas con Trastorno del Espectro Autista (TEA) (2015). Con esta iniciativa se buscó contar con un instrumento que permita orientar la sospecha y confirmación diagnóstica de personas con este trastorno del desarrollo, así como la realización de intervenciones efectivas basadas en la evidencia científica recopilada en el marco del Análisis del Comportamiento Aplicado (ABA).

Siguiendo lo estipulado en la ley estatutaria de salud (Ley 1751 del 16 de febrero de 2015) y, en especial, lo declarado en los artículos $5^{\circ}, 8^{\circ}$ y $15^{\circ 1}$, la aparición de dicho protocolo ha permitido tener una ruta clara para guiar la atención y los procesos de intervención dirigidos a la población con TEA, aun cuando este mismo señala que en Colombia no existen datos específicos que establezcan la prevalencia de este trastorno en el país y solamente se cuente con un estimado del 16\% para la población menor de 15 años que presenta algún tipo de trastorno del desarrollo

En el artículo $5^{\circ}$, se estipula que le corresponde al Estado "Formular y adoptar políticas que propendan por la promoción de la salud, prevención y atención de la enfermedad y rehabilitación de sus secuelas, mediante acciones colectivas e individuales", y "realizar el seguimiento continuo de la evolución de las condiciones de salud de la población a lo largo del ciclo de vida de las personas". En el artículo $8^{\circ}$ se dispone que "los servicios y tecnologías de salud deberán ser suministrados de manera completa (Principio de integralidad) para prevenir, paliar o curar la enfermedad". Finalmente, en el artículo 15, en relación con que los recursos públicos de la Salud no podrán destinarse a financiar servicios o tecnologías en los que "no exista evidencia científica sobre su seguridad y eficacia clínica” (MINSALUD, 2015a),
(Ministerio De Salud y Protección Social \& Instituto De Evaluación Tecnológica en Salud., 2015)². En esta misma línea, la Organización Mundial de la salud (OMS) en 2019, aseguró que Colombia cuenta con 115.000 casos aproximadamente de TEA, mientras que la Liga Colombiana de Autismo (LICA), estima que el $40.7 \%$ de las personas con TEA en Colombia se encuentran en Bogotá (Concejo de Bogotá, 2019).

Este panorama señala la importancia de generar estudios, no solo dirigidos a entender la situación actual de las personas con TEA y sus cuidadores sino, además, de todas las personas que conforman el núcleo familiar. Adicionalmente, esta investigación busca incorporar la perspectiva de los docentes que participan en los procesos educativos, con miras a que los resultados hallados a partir de la incorporación de la voz de cuidadores y docentes, actores centrales dentro de los procesos de inclusión, permitan nutrir la investigación en torno a dichos procesos y contribuyan en la divulgación de las iniciativas estatales dirigidas a intervenir este problema de salud pública.

\section{Educación inclusiva y TEA.}

La inclusión alude a un proceso de participación igualitaria de todos los miembros de una sociedad en sus diferentes áreas: económica, legal, política, cultural, educativa, etc. La inclusión se vincula con la cohesión, la integración y la justicia social, es un proceso que asegura el que todas las personas tengan las mismas oportunidades y los recursos necesarios para participar plenamente en la comunidad a la que pertenecen (Bejarano, 2020; Gil, 2009). Ainscow y Miles (2009, citados en Escribano y Martínez (2013) hacen referencia a cuatro elementos o principios que se han fortalecido en los últimos años y recomiendan tenerlos en cuenta a la hora de definir la inclusión. Los cuatro elementos son:

La inclusión es un proceso. Es una búsqueda constante para responder más y mejor a la diversidad en términos dinámicos, propios de un camino tortuoso y nada fácil. (p.22) 2. La inclusión identifica y elimina barreras. Señala la dificultad y los obstáculos con los que se encuentran los sujetos en el proceso de aprendizaje. El identificar las barreras es la primera medida para iniciar un mecanismo de eliminación progresiva. (p.22) 3. La inclusión busca la presencia, la participación y el éxito de todos los alumnos. La "presencia" que significa el lugar donde los niños son educados, con qué nivel de fiabilidad y de puntualidad asisten a las aulas; la "participación" se refiere a la calidad de sus experiencias dentro del colegio, incorpora la voz del alumno; y el "éxito" son los resultados del aprendizaje. (p.22) 4. La inclusión vela por los grupos de riesgo; provenientes de la marginación social, exclusión o bajo rendimiento, etc. Esto exige una supervisión continua para adoptar medidas que aseguren su presencia, participación y éxito dentro del sistema educativo. (p.22)

Ahora bien, en lo que respecta puntualmente a la educación inclusiva, se hace referencia a no excluir o segregar a ningún estudiante como consecuencia de su condición de diversidad, dificultad de aprendizaje, pertenencia a un grupo social o étnico determinado o bien por género (Wilches, 2015; Molano y Bejarano, 2017). Por el contrario, el desafío está en reconocer el valor de la diversidad como un bien en sí mismo, que a su vez enriquece la sociedad. Desde las ideas sobre inclusión se debe eliminar aquellas visiones que problematizan

Empero, un dato interesante que puede dar una idea general sobre la cantidad de personas con TEA en el país puede derivarse de la cantidad de tutelas registradas en Colombia para demandar servicios de atención e intervención dirigidos a personas con TEA. De acuerdo con cifras del Ministerio De Salud y Protección Social, mientras en el 2006 se ordenaron vía tutela 134 tratamientos con un costo de 236 millones de pesos, en el 2014 las órdenes se incrementaron a 31.186 terapias con un costo de 62.863 millones de pesos en todo el país (MINSALUD, 2015). 
la diferencia y la ven como amenaza, puesto que solamente ha contribuido a incrementar las desigualdades sociales; es imperativo encontrar mejores formas de responder a la diversidad y la diferencia (Wilches, 2015).

Entretanto, González (2008) plantea que, en el contexto educativo, la educación es inclusiva cuando se favorece a los niños y niñas con necesidades educativas especiales, en el quese obtiene como resultado una igualdad de oportunidades y participación, sin exclusiones, ni requisitos de entrada. Por otra parte, Casas y Aparicio (2016) afirman que el objetivo de una adecuada educación inclusiva consiste en dotar a los profesionales de herramientas y estrategias para favorecer el desarrollo de las competencias personales, la accesibilidad y comprensibilidad de los entornos en los que se desenvuelve y contribuir positivamente a su calidad de vida. Así las cosas, la inclusión alude, a un proceso de participación igualitaria de todos los miembros de una sociedad en sus diferentes áreas: económica, legal, política, cultural, educativa, etc.; se vincula con la cohesión, la integración y la justicia social, en un proceso que asegura el que todas las personas tengan las mismas oportunidades y los recursos necesarios para participar plenamente en la comunidad a la que pertenecen (Gil, 2009).

El país ha avanzado en el reconocimiento de la educación inclusiva como principio infalible en la búsqueda de la educación para todos: en ese sentido, el Ministerio de Educación Nacional (2017) ha adelantado iniciativas en todos los niveles de formación, atendiendo las orientaciones de organismos internacionales como la Unesco. El ministerio de educación en su Documento de Orientaciones técnicas, administrativas y pedagógicas para la atención educativa a estudiantes con discapacidad en el marco de la educación inclusiva , afirma que Colombia necesita una escuela centrada en el estudiante, en sus fortalezas, habilidades y potenciales; alejarnos de la carencia y el déficit para acercarnos a la persona misma, a sus posibilidades o potencialidades.

Ahora bien, en Colombia la población con necesidades educativas especiales (NEE), así como los procesos de educación inclusiva se encuentran amparados por una normatividad que incluye una serie de leyes y decretos. La Ley General de Educación 115 de 1994, por ejemplo, fundamentada sobre el derecho a la educación que tienen todas las personas, incluidas personas con limitaciones físicas, sensoriales y psíquicas, con capacidades excepcionales y personas que requieran rehabilitación social, al tiempo las respectivas adaptaciones curriculares a que haya lugar en caso de ser necesario. La Ley 1145 de 2007 que establece la política pública para las personas en condición de discapacidad en el marco de los derechos humanos. El Decreto 366 de 2009 por medio del cual se reglamenta la organización del servicio de apoyo pedagógico para la atención de los estudiantes con discapacidad, con capacidades o talentos excepcionales. La Ley Estatutaria 1618 de 2013 que establece las disposiciones para garantizar los derechos a personas en condición de discapacidad mediante medidas inclusivas y ajustes razonables; es de resaltar el artículo 11, que define la política y reglamenta el esquema de atención educativa, el acceso y la permanencia a una educación de calidad a personas con necesidades educativas especiales.

El Proyecto de Ley 046 de 2017 que tiene por objeto garantizar y asegurar los derechos de las personas con Trastorno del Espectro Autista (TEA), en igualdad de condiciones a las personas en situación de discapacidad en Colombia, brindándoles los apoyos y ajustes razonables que requieran para una efectiva inclusión, tal como la atención profesional para determinar el nivel de escolaridad y así dar paso a los respectivos ajustes razonables, o en su defecto establecer la necesidad de acompañamiento permanente dentro del aula escolar. El Proyecto de Ley 083 de 2015 que busca garantizar la atención integral y la protección de personas con Trastorno del Espectro Autista (TEA) teniendo en cuenta sus características individuales, esto incluye la oportunidad en el diagnóstico, intervención y acceso a la educación, inserción a la vida laboral y social incluyendo cultura, recreación y deporte.

El Decreto 1421 de 2017 que establece que todo estudiante con discapacidad a inicios de su proceso de escolarización, debe contar con un diagnóstico previamente establecido por el sistema de salud, que logre identificar el tipo de discapacidad que presenta. Así mismo se establece que en caso de no contar con un diagnóstico, se procederá con la matrícula y será la institución educativa quien a través del registro para la identificación de estudiantes con discapacidad SIMAT, reporte a la Secretaría de Educación para que se realice una articulación con el sector salud y así garantizar el diagnóstico y el respectivo proceso de atención. El decreto también presenta el Plan Individual de Ajustes Razonables - PIAR, que consiste en las adaptaciones, estrategias y/o apoyos necesarios por parte del sistema educativo para garantizar el desarrollo y aprendizaje para esta población. Se resalta la participación activa por parte de cuidadores o la familia, en los procesos escolares, fortalecer el compromiso que debe establecer las familias como actores fundamentales en la educación de sus hijos con diversidad funcional.

El Ministerio de educación propone cinco lineamientos pedagógicos para personas con diversidad funcional, dentro de ellas las personas con autismo; primero, un marco jurídico con leyes que ampara esta población, segundo la atención educativa, que trata sobre la igualdad y el derecho a la educación en instituciones tanto públicas como privadas, así como la adaptación del entorno; reducir factores distractores, recordatorios visuales, estructura y organización física de los puestos, puntos visuales, tercero, un plan de acción que atribuye la responsabilidad de aplicar esta política pública y la prestación del servicio educativo, a entes territoriales quienes se encargan de identificar y caracterizar a la población con necesidades educativas especiales, al tiempo de capacitar o formar al equipo de docentes, y las instituciones educativas quienes deben contar los recursos, que permitan brindar una educación de calidad, y quinto la evaluación, donde la Secretaría de educación en compañía del Ministerio de educación construirán los planes de evaluación en diferentes áreas a personas con diversidad funcional (Diazgranados, y Tebar, 2018).

Para el Ministerio de Educación (2017), se hace necesario la implementación de los materiales que permiten el acceso a los contenidos, estos pueden ser concretos o gráficos para ilustrar los conceptos o situaciones que se pretenden enseñar; "Comprenden dos grandes categorías: material gráfico y textos. Dentro del material gráfico pueden estar láminas, videos, modelos de trabajos terminados, dibujos, entre otros, que le permiten al estudiante comprender la temporalidad de los eventos, organizar sus acciones en secuencias lógicas e identificar la emoción que le producen las situaciones, además se debe tener en cuenta como punto importante la distribución de los espacios y la ambientación de ellos puesto que de esta manera el niño tendrá una idea de lo que se realizará" (citado por Diazgranados y Tebar, 2018 p. 29).

Es importante reconocer los avances que se han forjado en cuanto a la importancia de generar espacios inclusivos, donde prima la implementación de herramientas y estrategias que suplen las necesidades de la población en condición de discapacidad. Sin embargo, Ruiz (2014) en su trabajo acerca de la percepción que tienen algunos maestros sobre integración e inclusión de alumnos con alguna discapacidad, refleja un gran desconocimiento por parte de algunos maestros cuando se habla aulas inclusivas, suponen que el hecho de tener alumnos con discapacidad en un aula ordinaria ya la convierte 


\section{Barreras en los procesos de Educación Inclusiva dirigidosa niños con Trastorno delEspectro Autista(TEA)}

\section{Estudio cualitativo con docentes de una institución educativa}

en aula inclusiva, sin hacer las modificaciones a que debe haber lugar. Adicional, se tiene la concepción errónea de que los profesionales de la salud, son los únicos que deben ocuparse de este tipo de trastornos, y aunque sus intervenciones son fundamentales en los tratamientos, muchos de los niños con TEA pasan gran parte del día en las aulas educativas, por ende, el docente se ubica en una posición primordial frente a la necesidad de conocimiento de este trastorno.

\section{Metodología.}

Esta investigación asumió un enfoque cualitativo. De acuerdo con Navarrete (2004) la investigación cualitativa incluye un conjunto de procedimientos metodológicos que utiliza palabras, textos, discursos, dibujos, gráficos e imágenes para comprender la vida social y sus significados, desde una perspectiva holística (Flick, 2004). . El objetivo de la investigación cualitativa es el conocimiento del significado que tiene una acción para el otro por lo que puede resultar pertinente para desarrollar abordajes que busquen explorar experiencias personales y particularidades diferenciales de los grupos sociales (Balcázar, González, López, Gurrrola y Moysén, 2013). Para el caso puntual de esta investigación, el desarrollo de un estudio cualitativo permitió explorar a profundidad las narrativas, opiniones y percepciones de los docentes en torno a los procesos de inclusión, de modo sea posible generar un aporte a este tema tomando como fuente de evidencia las voces de los docentes en tanto actores centrales del proceso educativo.

\section{Diseño:}

Para esta investigación se implementó un diseño de Teoría Fundamentada el cual es definido por Strauss y Corbin (2002) como un diseño y un método de análisis cualitativo de datos obtenidos como resultado de entrevistas en profundidad o semiestructuradas. Se utilizan también observaciones directas que pueden ser registradas en video o en fotografía y que, en cualquier caso, deben tener un registro escrito. La teoría fundamentada sirve como un método para construir teorías que emerjan basadas en datos recolectados minuciosamente; es decir, a través de los procedimientos analíticos, se construye teoría que está fundamentada en los datos, de ahí su nombre (De la Cuesta, 2006).

\section{Técnicas de recolección de la información}

Para esta investigación las técnicas de recolección de la información empleadas fueron:

$\rightarrow$ Entrevistas semiestructuradas: Según Witzel (1982,1985, como se cita en Flick, 2007) utiliza una guía de entrevista que incorpora preguntas y/o estímulos narrativos, es posible recoger datos biográficos respecto a cierto problema. Este tipo de entrevista se caracteriza bajo tres criterios principales: centrarse en el problema, es decir, la orientación del investigador hacia un problema social pertinente, la orientación al objeto; que los métodos se desarrollan o modifican con respecto a un objeto de investigación y la orientación al proceso.

$\rightarrow$ Grupos focales: De acuerdo con Hernández, Baptista y Fernández (2014) los grupos focales buscan identificar cómo los individuos forman un esquema o perspectiva de un problema a través de la interacción.

Se consideran como una especie de entrevistas grupales, las cuales consisten en reuniones de grupos pequeños o medianos (tres a 10 personas), en las cuales los participantes conversan en torno a uno o varios temas en un ambiente relajado e informal, bajo la conducción de un especialista en dinámicas grupales (Hernández, Fernández, y Baptista,

\section{0, p. 425).}

$\rightarrow$ Observación participante: el investigador mantiene experiencias directas con los participantes y el ambiente (Hernández et al., 2014).

\section{Población:}

Para esta investigación se tuvo en cuenta como criterio de selección de la población a docentes titulares (maestro titular de la asignatura) que trabajaran en entidades educativas con mínimo de 5 años de experiencia en procesos de educación inclusiva y específicamente como característica central de niños diagnosticados con Trastorno del Espectro Autista (TEA). También se tomó en cuenta como población participante a docentes de apoyo (docentes que sirven de apoyo al docente titular en el trabajo de niños con necesidades educativas especiales (NEE)), y que tuvieran una experiencia mínima de 5 años en procesos de educación inclusiva, estos docentes por lo general están dentro del aula trabajando de manera individual y grupal con estos niños; en este caso niños con TEA, brindando un apoyo al docente titular frente a los planes de trabajo en el aula.

\section{Procedimiento:}

Fase I: Alistamiento, allí se realizó una revisión documental y teórica, así como también se delimitó la población; en este caso, la población seleccionada estuvo constituida por docentes titulados y por docentes de apoyo que tuvieran como mínimo 5 años de experiencia en docencia dirigida a niños diagnosticados con TEA.

Fase II: Recolección y análisis de datos. De acuerdo con la revisión teórica y la observación participante se estructuró y se aplicó el primer protocolo de entrevista semiestructurada (ver anexo 1), se analizaron los datos (cada investigador de forma individual y luego de forma grupal entre investigadores), de allí surgieron las primeras categorías con las que se estructuró y se aplicó el segundo protocolo de entrevista semiestructurada (ver anexo 2), con el método anteriormente nombrado se analizaron nuevamente los datos, que condujeron a la identificación y definición de las categorías, con las que se elaboró y aplicó un tercer protocolo de grupo focal (ver anexo 3), una vez más se realizó el análisis de los datos que condujeron a la saturación de categorías.

Fase III: Estructuración de la teoría. En esta fase se analizó la información en general para dar paso a una propuesta teórica basada en los datos obtenidos.

\section{Técnica de análisis}

Siguiendo los postulados de la Teoría Fundamentada (Corbin y Strauss, 1998), la técnica para análisis de la información fue la codificación teórica. De acuerdo con Strauss y Corbin (1998) en este diseño los investigadores descubren, a través de la revisión detallada de los datos, línea por línea, conceptos y relaciones, construyendo así de forma sistemática las categorías de acuerdo con sus propiedades y dimensiones en cada una de sus tres fases;

$\rightarrow$ Codificación abierta: "Es el proceso analítico por medio del cual se identifican los conceptos y se descubren en los datos sus propiedades y dimensiones" (Strauss y Corbin 1998, p. 110)

$\rightarrow$ Codificación axial: "Proceso de relacionar las categorías a sus subcategorías, denominado "axial" porque la codificación ocurre alrededor del eje de una categoría, y enlaza las categorías en cuanto a sus propiedades y dimensiones" (Strauss y Corbin 1998, p. 134) 
$\rightarrow$ Codificación selectiva: La codificación selectiva es el proceso de refinar e integrar la teoría. En la integración, las categorías se organizan alrededor de un concepto explicativo central. La integración se da con el correr del tiempo; comienza con los primeros pasos en el análisis, y a menudo no termina sino en la escritura final. Una vez que se establece compromiso con una idea central, las categorías principales se relacionan con ella por medio de las oraciones que explican las relaciones (Strauss y Corbin 1998, p. 177).

$\rightarrow$ En el siguiente cuadro se ilustran algunas de las categorías obtenidas en la codificación abierta, en la codificación axial y aquellas resultantes en la codificación selectiva:

Tabla 1. Ejemplo de códigos emergentes en cada una de las fases de análisis

\begin{tabular}{|c|c|c|}
\hline $\begin{array}{c}\text { Codificación } \\
\text { Abierta }\end{array}$ & Codificación Axial & $\begin{array}{c}\text { Codificación } \\
\text { Selectiva }\end{array}$ \\
\hline 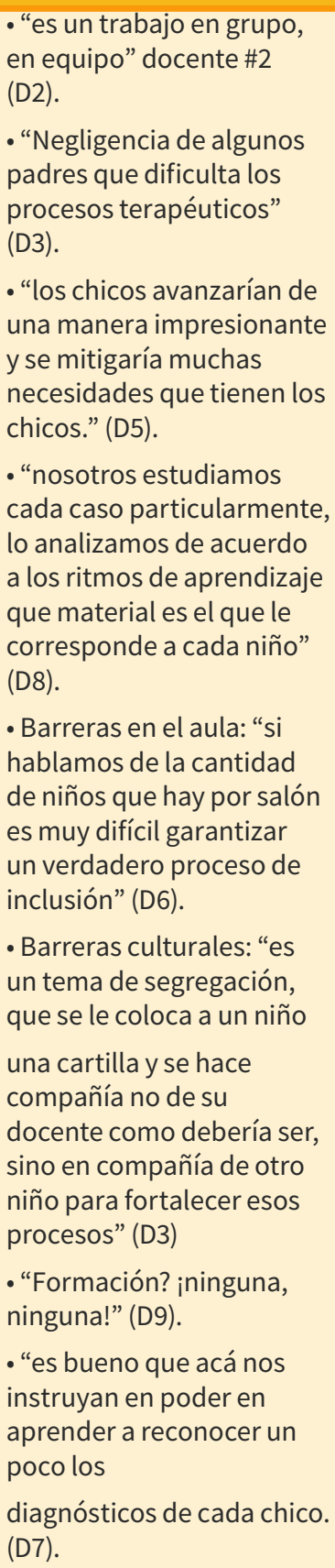 & $\begin{array}{l}\text { 1. participación de } \\
\text { cuidadores para el éxito de } \\
\text { los procesos educativos. } \\
\text { 2. Ajustes curriculares } \\
\text { y pedagógicos que } \\
\text { consideren la variabilidad } \\
\text { del TEA. } \\
\text { 3. Procesos de formación a } \\
\text { docentes sobre el TEA. } \\
\text { 4. Rol del docente. } \\
\text { 5. Acompañamiento } \\
\text { permanente en el aula. } \\
\text { 6. Estrategias inclusivas } \\
\text { implementadas en la } \\
\text { institución. } \\
\text { 7. Rol de los entes } \\
\text { gubernamentales. }\end{array}$ & $\begin{array}{l}\text { 1) Barreras asociadas } \\
\text { a los procesos de } \\
\text { formación profesional } \\
\text { para la diversidad. } \\
\text { 2) Barreras asociadas } \\
\text { a la participación de } \\
\text { cuidadores en los } \\
\text { procesos de educación } \\
\text { inclusiva. } \\
\text { 3) Barreras asociadas } \\
\text { al uso de mediaciones } \\
\text { y estrategias } \\
\text { pedagógicas y } \\
\text { didácticas para su uso } \\
\text { en el aula de clase. } \\
\text { 4) barreras asociadas a } \\
\text { factores normativos y } \\
\text { socioeconómicos. }\end{array}$ \\
\hline
\end{tabular}

Fuente: elaboración propia

$\rightarrow$ Consideraciones éticas: De acuerdo con los principios establecidos en la Resolución 08434 del 4 de octubre de 1993 cabe resaltar que la presente investigación se considera como investigación sin riesgo ya que está dentro de los estudios que emplean técnicas y métodos de investigación documental retrospectivos y aquellos en los que no se realiza ninguna intervención y modificación intencionada a las variables biológicas, fisiológicas, psicológicas o sociales de los individuos que participan en el estudio como lo menciona el artículo 10 de la Resolución 08430 de 1993.

\section{Resultados}

Producto del ejercicio de análisis de datos y siguiendo el muestreo teórico de la teoría fundamentada (Corbin y Strauss, 1998), se aplicaron 10 entrevistas semiestructuradas individuales y un grupo focal (Ibid, 2014) a docentes titulares y docentes de apoyo. La investigación contó con un total de 12 participantes; algunos de ellos (4) participaron tanto en las entrevistas individuales como en el grupo focal. Para garantizar la credibilidad y validación en los resultados obtenidos, se realizó una triangulación entre técnicas y triangulación de datos entre los investigadores, todo lo cual permitió llegar a la saturación de una categoría central: barreras que limitan la inclusión. En el proceso de dimensionalización de esta categoría central emergieron como subcategorías: 1) Barreras asociadas a los procesos de formación profesional para la diversidad; 2) Barreras asociadas a la participación de cuidadores en los procesos de educación inclusiva; 3) Barreras asociadas al uso de mediaciones y estrategias pedagógicas y didácticas para su uso en el aula de clase; 4) barreras asociadas a factores normativos y socioeconómicos.

A continuación, se detalla el modo en que procedió al proceso de análisis de acuerdo con los supuestos de la codificación teórica.

\section{Codificación abierta:}

En un primer momento se realizó el diseño de un primer protocolo de entrevista semiestructurada de acuerdo a los datos obtenidos en la revisión teórica. En la aplicación de dicho protocolo se encontraron 265 códigos. En coherencia con el diseño metodológico, un código se entiende como aquellos términos inducidos por los investigadores que condensan el significado de las unidades de análisis escogidas (párrafos) o como aquellas palabras o expresiones tomadas textualmente del discurso de los participantes (i.e. códigos in vivo) (Hernández, Fernándezy Baptista, 2014) (ver tabla 1). Luego de realizar la transcripción de las entrevistas, el equipo de investigadores desarrolló un análisis individual que posteriormente se sometía a un proceso de triangulación entre miembros del equipo de investigación (Flick, 2004). Producto de este ejercicio de triangulación fueron emergiendo las primeras categorías axiales. Esta triangulación se desarrolló tomando como insumo inicial el análisis individual desarrollado por cada investigador y, posteriormente, el contraste y visión de dichos datos de forma grupal, todo con el fin de identificar conjuntamente las categorías abiertas.

\section{Codificación axial:}

Derivado de los primeros códigos obtenidos en la codificación abierta (265) se realizó la estructuración de un segundo protocolo. Como resultado de la aplicación de este segundo protocolo se evidenció una reducción en la cantidad de códigos inicialmente identificados y se procedió a generar una estructuración de categorías más sólida. Se realizó la transcripción de las entrevistas de forma individual y la identificación de códigos conceptuales por parte de cada investigador. Posteriormente se realizó una comparación de estos códigos axiales entre investigadores siguiendo los mismos lineamientos descritos en la fase de la codificación abierta (triangulación entre investigadores) . El cual dio origen a la consolidación de 7 categorías. A continuación, se hace referencia a estas categorías acompañadas de algunos códigos in-vivo.

1. Participación de cuidadores para el éxito de los procesos educativos: de acuerdo a lo manifestado por los docentes participantes se logra identificar como un factor fundamental en el proceso de educación inclusiva, la participación de los cuidadores o padres de familia debe ser de forma activa. Estas percepcio- 


\section{Barreras en los procesos de Educación Inclusiva dirigidos a niños con Trastorno del Espectro Autista (TEA)}

Estudio cualitativo con docentes de una institución educativa

nes se respaldan por los participantes "es un trabajo en grupo, en equipo” (D2), el que permitirá un mayor avance en cada niño. Se resalta repetidamente la importancia de la participación de manera constante y pertinente de acuerdo a lo que se desea trabajar con el niño según sus necesidades; es clave señalar que de no ser así puede generar retrocesos en los procesos educativos, al manifestar que la "Negligencia de algunos padres dificulta los procesos terapéuticos" (D3). Al abordar este tipo de percepciones y hacer referencia a una "negligencia" se debe indagar e identificar; si es de tipo presencial, conceptual, económica, material, entre otras.

2. Ajustes curriculares y pedagógicos que consideren la variabilidad del TEA: Aquí se logra identificar que de acuerdo a la variabilidad del TEA y frente a las necesidades de esta población específicamente en el ámbito educativo, los docentes manifiestan que uno de los requerimientos principales es la plena identificación de características y necesidades individuales, como lo afirman los docentes participantes "los chicos avanzarían de una manera impresionante y se mitigaría muchas necesidades que tienen." (D5). De acuerdo a lo anterior, es fundamental que estos procesos se hagan con rigurosidad ya que, como manifestó uno de los participantes: "nosotros estudiamos cada caso particularmente, lo analizamos de acuerdo a los ritmos de aprendizaje y qué material es el que le corresponde a cada niño"(D8). Dicha categoría da lugar a que se investigue a profundidad qué tipo de ajustes se están adelantando hasta el momento y si están considerando dicha variabilidad.

3. Procesos de formación a docentes sobre el TEA: En este punto es necesario que los docentes tengan el conocimiento pleno de las características, competencias y necesidades de un niño con TEA (como población directa en el proceso educativo). Esta categoría predominó en la codificación axial y se vio reflejada en los participantes al manifestar carencia de conocimiento y/o formación que tienen los docentes titulares o de apoyo al hablar de autismo, quedó en evidencia al preguntar por los procesos de capacitación en la formación académica y posgradual: "Formación? Ninguna, ninguna" (D9). Es necesario que las instituciones de formación superior, Ministerio de Educación, instituciones de educación inclusiva y en general, fortalezcan los procesos de capacitación al colectivo educativo; para los docentes es indispensable "promover procesos de capacitación y es necesario que eso ocurra" (D5), "es bueno que acá nos instruyan en poder aprender a reconocer un poco los diagnósticos de cada chico. (D7).

4. Rol del docente: Cuando se indaga en el papel que están cumpliendo los docentes dentro de los procesos de formación a niños con TEA dentro del marco de la educación inclusiva, los participantes manifiestan que es uno de los papeles principales, sino el primordial. Para uno de los entrevistados es un "rol de liderazgo y apoyo" (D1), mientras que para otro participante "todo el tiempo siempre estamos ahí en ese proceso de inclusión, desde el docente titular hasta el docente de apoyo, este último cumpliendo un proceso de acompañamiento individual con el estudiante con TEA... todo parte desde el acompañamiento, que sea un buen acompañamiento, de brindarle herramientas, pero no hacerle todo." (D4) es importante otorgarle al estudiante herramientas que fomenten la autonomía e independencia.

5. Acompañamiento permanente en el aula: En el transcurso de la aplicación del segundo protocolo, se logró identificar en los relatos y a través de la observación realizada dentro de las aulas, la carencia significativa en el acompañamiento permanente en los procesos pedagógicos/educativos de los niños con TEA. Dentro del aula de clase se encuentra el docente titular, los estudiantes regulares o neurotípicos, los niños con NEE o en este caso con TEA y los docentes de apoyo, que son los que brindan el acompa- ñamiento específico para estos niños; gran parte de los docentes de apoyo están contratados por los familiares de cada niño para que realicen ese acompañamiento permanente e individual, otros han sido otorgados por instancias legales como tutelas a través de las entidades promotoras de salud (EPS) y otros niños simplemente no tienen este acompañamiento ya sea por recursos económicos o de otra índole.

Según lo señalado por los docentes participantes y lo observado por los investigadores se logró identificar que hay una cantidad mínima de estos docentes en referencia a la cantidad de niños con autismo en el aula de clase. Por tanto, es complejo para el docente titular el adecuado acompañamiento para cada estudiante, pues debe abarcar a todos los estudiantes y cada uno con un proceso de aprendizaje diferente. Como se afirma "se necesitan más docentes de apoyo" (D5). Teniendo en cuenta la importancia de este acompañamiento para garantizar la viabilidad de los programas de intervención, para los entrevistados es esencial que cada niño con autismo cuente con un docente de apoyo o acompañante permanente como se relata "considero yo que sí es fundamental que los estudiantes tengan un acompañamiento constante" (D8).

6. Estrategias inclusivas implementadas en la institución: Dentro del marco de la educación inclusiva, surge un interrogante importante y es, ¿qué tipo de estrategias se implementan para ofrecer una adecuada educación de acuerdo a las necesidades de los estudiantes con TEA? Los participantes las señalan en sus narraciones; "Lo primero que uno debe reconocer es qué tipo de diagnóstico tiene cada estudiante" (D7) lo anterior con el fin de generar estrategias de intervención a nivel educativo. Aquí se resaltan algunas estrategias; "tenemos un proceso de evaluación con familia" (D6), otros como "la ubicación del estudiante dentro del aula" (D5) y "el tema de los pictogramas, sea verbal o no verbal, eso es vital" (D5) el uso de estos "pictogramas" es una de las estrategias más señaladas y utilizadas dentro y fuera de aula de clase dentro del contexto educativo. Otras de las estrategias nombradas y utilizadas fueron; "material de apoyo como material lúdico pedagógico, salón de inclusión y biblioteca" (D3).

7. Rol de los entes gubernamentales: Para los participantes además de la comunidad educativa, los cuidadores y/o padres, el trabajo interdisciplinar e interinstitucional contribuye al éxito del proceso educativo de los niños con TEA. Según sus narrativas hay niños que no reciben los procesos terapéuticos pertinentes para su diagnóstico, otros no han sido diagnosticados, no hay oportunidad en las citas médicas, las familias no reciben el apoyo necesario a nivel social, de formación y sensibilización, aspectos fundamentales como el derecho a un cupo escolar. Según lo manifiesta el participante "un cuidador también debe recibir por parte de las EPS o las instituciones educativas una capacitación y una sensibilización del proceso porque no es fácil" (D7) "Es un equilibrio muy simple que requiere desde la política pública una implementación desde estrategias pedagógicas" (D7). Para algunos docentes es "falta de voluntad, falta de cumplimiento por las normas establecidas" (D8).

\section{Codificación selectiva}

Derivado de la reducción de categorías originadas en la codificación axial, se generó un tercer protocolo para grupo focal, que permitió la triangulación entre técnicas (Flick, 2004). Con los resultados obtenidos y los constantes procesos de triangulación entre investigadores, se llegó a la conclusión que estas categorías tenían una característica principal que las representaba, conllevando a la saturación según lo propuesto en el diseño de teoría fundamentada; se obtuvo como categoría central para cuidadores y docentes "barreras que limitan la 
inclusión" esta categoría representa y agrupa de manera macro cada una de estas subcategorías. Al dimensionalizarla emergieron como subcategorías: 1) Barreras asociadas a los procesos de formación profesional para la diversidad; 2) Barreras asociadas a la participación de cuidadores en los procesos de educación inclusiva; 3) Barreras asociadas al uso de mediaciones y estrategias pedagógicas y didácticas para su uso en el aula de clase; 4) barreras asociadas a factores culturales y socioeconómicos. de ellas:

A continuación, se detallan los elementos específicos de cada una

1. Barreras asociadas a los procesos de formación profesional para la diversidad: Se logra identificar que una de las grandes barreras para que los procesos de educación inclusiva se lleven a cabo con éxito, están relacionados con la formación que tienen los docentes frente a la diversidad. A continuación, algunas definiciones de autismo por parte de los participantes: "movimientos repetitivos, gritos o conductas disruptivas" (D6), "Niños con necesidades diferentes" (D1), "ecolalias, movimientos estereotipados, sus relaciones sociales no son iguales, tienen dificultades en los procesos de lenguaje, de verbalización, dificultades en la asociación y apropiación de relacionarse con el otro, psicorígidos y rutinarios" (D3). Son los docentes quienes manifiestan vacíos conceptuales y de manejo de este tipo de población, para ellos es necesario "mayor información y materiales sobre el TEA" (D1).

De acuerdo con Frith, (2003), por la variabilidad y alteraciones que tiene los niños con TEA, es necesario un conocimiento profundo al momento de realizar cualquier intervención, en este caso el ámbito educativo; pero lastimosamente esto no sucede en los docentes titulares y de apoyo quienes manifiestan que es necesario "Capacitación permanente" (D5). Según refieren los participantes, puntualmente los docentes titulares, nunca en su trayectoria educativa de pregrado recibieron formación alguna sobre niños con NEE, cómo abordarlos dentro del aula, en su lugar de trabajo, como lo manifiestan: "hemos recibido una que otra capacitación” (D7). Lo que deja un fuerte interrogante; ¿Cómo se están llevando los procesos de educación inclusiva si los docentes no tienen pleno conocimiento de la población con la que están trabajando? Esto conlleva a demostrar en esta investigación las barreras que realmente están afectando los procesos de educación inclusiva en la ciudad de Bogotá.

2. Barreras asociadas a la participación de cuidadores en los procesos de educación inclusiva: En este punto de la investigación los docentes participantes reiteran en sus narraciones que la participación de los cuidadores o padres de niños con autismo, es fundamental para garantizar un proceso educativo inclusivo exitoso. Para ellos es sustancial que el cuidador se comprometa de forma diligente en el proceso educativo del niño con TEA, "es un proceso que sale del colegio y se sigue en la casa" (D4), si realmente se quiere un avance significativo es fundamental, "acompañamiento por parte de padres" (D2).

Como afirma nuestro participante "las familias en muchos casos no están preparadas para asumir la realidad de tener un niño especial" (D7), esto puede llevar a un manejo erróneo frente a la educación de sus hijos. Los docentes participantes manifiestan "sí una familia tiene capacitaciones, de conocimiento, créeme que el papel de la escuela se va hacer mucho más fácil" (D7), para otros, también se ven afectados los canales de comunicación entre escuela y familia según refieren: " $a$ veces entran en choque con los profes, en que ellos creen que él puede hacer esto, es como "iusted no sabe profe, yo si sé!" (D8) aquí se logra identificar que en algunas ocasiones no hay comunicación asertiva y directa entre docentes y cuidadores. Es crucial para los docentes que se fortalezcan los canales de comunicación entre la escuela y los pa- dres, que los padres tengan una participación activa en la educación de sus hijos y que sean comprometidos, "acompañamiento serio por parte de la familia" (D8).

3. Barreras asociadas al uso de mediaciones, estrategias pedagógicas y didácticas para su uso en el aula de clase: Estas herramientas varían de acuerdo al docente y su formación o conocimiento. Como se había señalado anteriormente, la formación ha sido una de las grandes barreras y que de cierto modo termina influyendo en la construcción de dichas estrategias. Los docentes han ido encontrando y compartiendo entre sí, diversas herramientas para trabajar dentro del aula, gracias a sus experiencias prácticas, experiencias de otros colegas y su propia búsqueda individual. En este punto importante tener en cuenta la variabilidad del TEA (plan de estudios según las necesidades del niño). Se implementan diferentes herramientas, "cartillas de trabajo prediseñadas como estrategia pedagógica y plan curricular con unos logros a cumplir" (D3), para otros docentes participantes simplemente el niño tiene que "adaptarse" a su plan de trabajo "generar autonomía exigida por el sistema educativo" (D1).

Cuando se habla de estrategias, una de las más usadas dentro del aula de clase por parte de las instituciones y docentes titulares, es el uso de docentes de apoyo o acompañantes para niños con NEE, se trabaja de manera individual con cada estudiante o en grupos focales pequeños, en los cuales se les facilita herramientas para el desarrollo de los planes de intervención. Lastimosamente este acompañamiento no se da de forma proporcional para todos los estudiantes con TEA, los entrevistados manifiestan "dificultad para el acompañamiento permanente en las aulas de clase" (D3), "se necesitan más docentes de apoyo" (D6), "los chicos deberían tener cada uno, una persona que los apoye" (D8). La ausencia de trabajo personalizado para el niño con TEA, dificulta los procesos educativos inclusivos.

A falta de docentes de apoyo el docente titular incurre en otras estrategias; "Se ubican en un mismo salón, pero se diferencia el aprendizaje con ellos" (D1), "Trabajo grupal como estrategia de inclusión" (D3); métodos o enfoques como: "he estado utilizando conductismo con los chicos que estoy" (D4); compañeros regulares de clase que sirven como estrategia: "Trabajo con pares" (D2), "que un niño y/o niña más pilo está al lado de niño TEA" (D5), "los niños en condición compartiendo el aula con los niños regulares, esa es la forma" (D8). No obstante, es inminente que la necesidad de un acompañamiento permanente dentro del aula, que garantice a los estudiantes con TEA un desarrollo, planeación, seguimiento y evaluación de los procesos educativos. Según manifiestan los participantes "Los acompañamientos son una herramienta muy útil" (D6) y "un acompañamiento adecuado también es fundamental para los procesos tanto educativos como sociales del niño" (D4).

4. Barreras asociadas a factores culturales y socioeconómicos: Barreras culturales como las ideas generalizadas que se tienen sobre lo que es el autismo; patrones de comportamiento y estereotipos e incluso los procesos de afrontamiento del diagnóstico por parte de los familiares y la comunidad en general, originan una brecha en los niños y su proceso educativo. Se mencionan aspectos como pautas de crianza, procesos de obtención y asimilación del diagnóstico en los padres, según refieren los participantes para algunos padres "entran en un luto de que no va a ser normal por los imaginarios que se tienen" (D4), el hecho de tener un niño con autismo en algunos cuidadores genera cierta clase de referencias y pautas que están marcadas culturalmente en el manejo de esta población, sin tener en cuenta que estas "creencias" sean correctas o erróneas.

5. Barreras como: "segregación" (D3), "falta de sensibilización" (D1) "Evitar los rótulos o las etiquetas" (D5) se dan en la comunidad en 


\section{Barreras en los procesos de Educación Inclusiva dirigidos a niños con Trastorno del Espectro Autista (TEA)}

Estudio cualitativo con docentes de una institución educativa

general por la poca información que se tiene del TEA. Para los docentes participantes, el ingreso de estudiantes con autismo a las instituciones educativas, es un derecho que no se brinda en gran parte de los colegios o escuelas, "que todos los colegios de Bogotá sean colegios que incluyan, todos" (D8), "debe haber procesos de inclusión en todos los colegios" (D5), la falta de inclusión en todos los colegios hace que los niños con NEE se concentre en las pocas instituciones que si cobijan esta población, para los docentes esto se convierte en algo que se sale de sus recursos, el manejar una cantidad significativa de niños con autismo.

Aquí algunas narrativas que sustentan lo anterior: "un curso donde se hacen procesos de inclusión no debe haber más de 20 niños, por temas de ruido, concentración y organización" (D5), "entre menos chicos haya va a haber mucho más control" (D4), "una maestra que tiene 30 niños ¿cómo se dedica un rato a ese niño? No es nada funcional. jhay un alto impacto!" (D1). Para la población muestra de esta investigación las barreras de índole económica no es menos importante, "hay familiares que no tienen los recursos" (D4), "hay niños que las mamás no tiene la posibilidad de pagar una persona de apoyo" (D9). Se relatan casos donde existe niños que no reciben un desayuno en su casa antes de ir a la escuela por falta de recursos económicos, niños que viven a distancias considerables de las instituciones incluyentes y no pueden asistir de forma regular porque no tienen quien los lleve o asuma el costo de los transportes, además obtener un beneficio de ruta es complejo y a veces es necesario instaurar tutelas.

La síntesis de estos resultados se presenta en el siguiente gráfico.

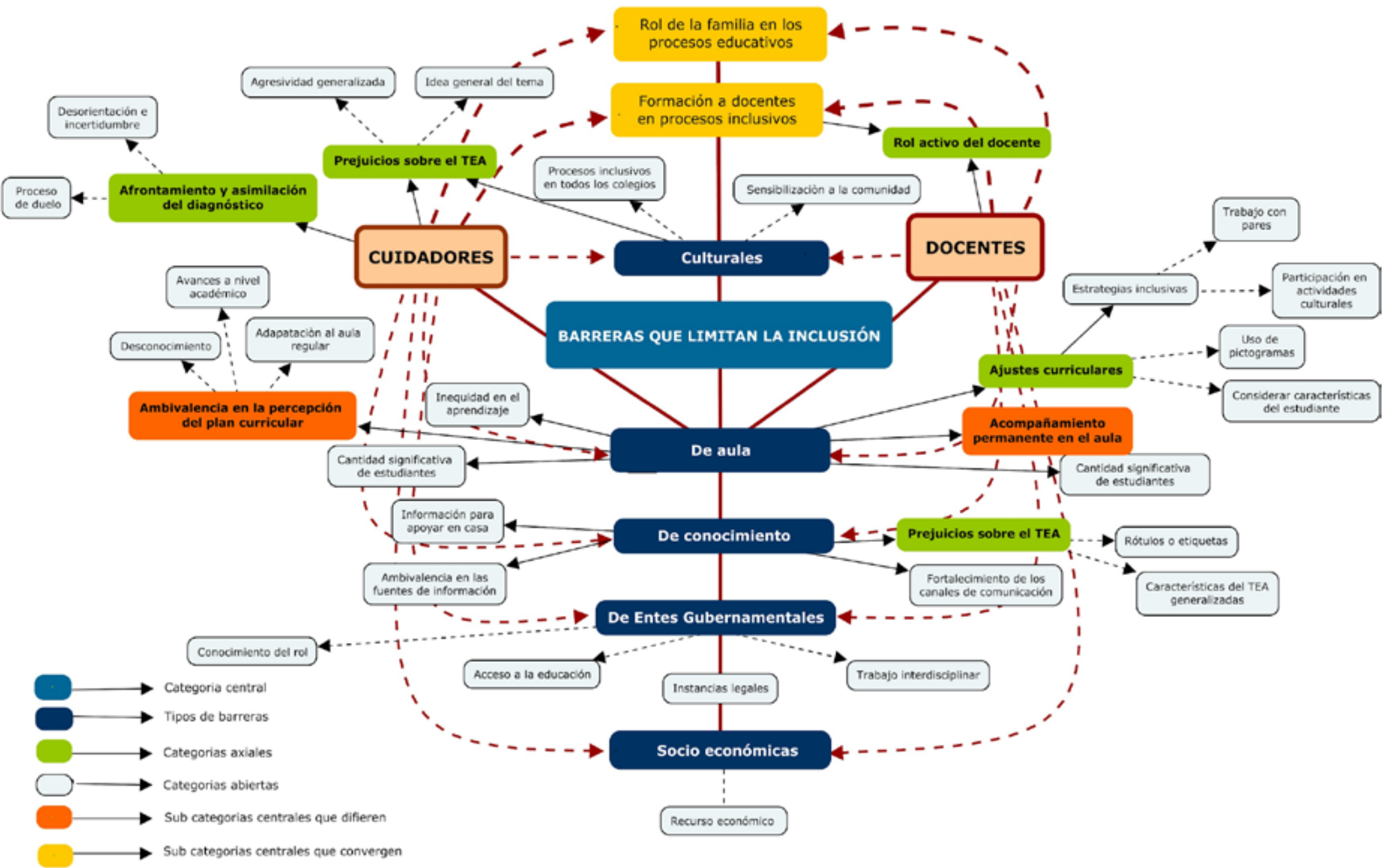

\section{Discusión de Resultados}

A partir de los resultados, se infiere que de las barreras que limitan los procesos de educación inclusiva en niños con TEA se desprenden barreras asociadas a la formación profesional para la diversidad, barreras asociadas a la participación de cuidadores, barreras asociadas a las estrategias pedagógicas y didácticas en el aula de clase y barreras asociadas a factores socioeconómicos y culturales. Se abordó de manera detallada de acuerdo a los relatos de los participantes como estas barreras afectan el proceso educativo del estudiante y por lo cual dichas barreras dejan ciertos interrogantes que se discuten a continuación:

\section{¿Cómo superar las barreras asociadas a los procesos de formación profesional para la diversidad?}

Al abordar la barrera asociada a la formación docente, los relatos dieron a conocer la carencia que existe de la misma en docentes titulares, se hace vital que desde el principio los maestros construyan repertorios de acciones inclusivas dentro del concepto de aprendizaje que desea brindar con su pedagogía (Bareño, 2015). Algunos docentes participantes manifiestan: "no tengo ningún tipo de formación sobre el autismo" (D7), "un docente que no posee las herramientas suficientes y por ende no brindará un adecuado proceso de formación" (D7). Algunos de ellos proponen "diplomados frente a temas pedagógicos, temas con- 
ductuales y estudios de Caso" (D5), "mayor información y materiales sobre el TEA" (D1); todo esto para garantizar una educación inclusiva, no solo de tener acceso a un cupo escolar, en un salón de clase, sino brindar todo un programa de intervención educativa al estudiante donde se le respeten y garanticen cada una de sus necesidades siempre con el propósito de propiciar autonomía en el estudiante (Marco, 2011).

Es importante que haya una formación inicial en los docentes, pero cuando esto no ocurre, la formación debe ser de carácter voluntario y permanente por parte del docente teniendo en cuenta su "rol de liderazgo y apoyo" (D1), donde haya empeño y compromiso por parte del maestro y del sistema educativo (Zapata, 2019). Un docente que realmente este comprometido con el proceso de inclusión tendrá la capacidad y autonomía de buscar nuevas estrategias, indagar, ponerlas en práctica y compartirlas; la apertura al aprendizaje se convierte en un factor fundamental para el docente. Por parte de las instituciones educativas es necesario que se brinden espacios pedagógicos para los docentes y profesionales del sector educativo, donde compartan herramientas, experiencias, avances científicos, investigaciones y modelos de intervención; esto proporciona y garantiza mejores herramientas de inclusión no solo al docente, sino a la calidad de vida del estudiante con TEA (Casas y Aparicio, 2016).

\section{¿Cómo superar las barreras asociadas a la participación de cuidadores en los procesos de educación inclusiva?}

Las familias, padres y cuidadores cumplen un papel muy importante en el proceso educativo del estudiante con TEA, ya que las interacciones entre comunidad educativa y familia fortalecen el proceso de inclusión (Calvo, 2009). Cuando un niño es diagnosticado con autismo, este diagnóstico ejerce cambios significativos en cada uno de los integrantes de la familia desde el proceso de afrontamiento hasta sus actividades diarias, enfrentándose a una realidad no deseada (De Goñi, 2015). No contar con un adecuado acompañamiento para estas familias puede generar como lo refieren Catalano, Holloway y Mpofu (2018) "síndrome del cuidador", una condición de agotamiento, enojo, ira o culpabilidad, y que de cierta manera termina influyendo en el contexto académico y calidad de vida del niño con TEA "mientras más se demoren en asumirlo se va a demorar mucho más los procesos del niño" (D7) "no pueden normalizar a sus hijos" (D5) "son niños con necesidades diferentes" (D1) Cuando esto se logra en los padres se facilitan los procesos de inclusión.

Es elemental que se logre instaurar en los padres y cuidadores, compromiso "necesario para aumentar efectividad de los procesos educativos (D1) siempre y cuando se le ofrezca a la familia la integración de forma gradual y adecuada a los procesos educativos que se desean trabajar con el niño (Milla y Mulas, 2009). Generar espacios en los que las familias participen de forma activa y directa en los procesos académicos del estudiante con TEA es una tarea de las instituciones educativas. Siempre fortaleciendo los canales de comunicación escuela-familia, la escuela puede y está en la obligación de resolver las dudas que presenten los cuidadores frente a los planes curriculares que se vienen adelantando con los alumnos; hacerlos participes de las actividades de inclusión que se pretenden trabajar siempre y cuando se identifique y respeten los tiempos en los que las familias pueden participar de acuerdo a las necesidades de cada hogar; "es un proceso que sale del colegio y se sigue en la casa" (D4).

\section{¿Cómo superar las barreras asociadas al uso de mediaciones, estrategias pedagógicas y didácticas para su uso en el aula de clase:}

Frente a estrategias y herramientas en los procesos educativos hay una estrecha relación con la formación y capacitación de docentes y los recursos que permitan brindar una educación de calidad a esta población (Diazgranados y Tebar, 2018). Se logra identificar que algunos docentes tienen en cuenta estrategias como: "Identificación de las necesidades para establecer un plan de trabajo" (D1), "adaptaciones curriculares dependiendo la funcionalidad del estudiante" (D3), Profundización en áreas específicas "proceso lógico matemático y proceso lecto-escritor" (D3), trabajo grupal como estrategia de inclusión, planes curriculares con unos mínimos a cumplir "generalmente buscamos que lea y escriba, haga las operaciones básicas y llegue a una comprensión" (D2), "lo que buscamos es que este con pares, uno a uno, por imitación, los chicos jalonan mucho" (D5).

Para otros maestros es claro afirmar: "uno no puede estar sentado con el chico" (D9), "Yo le dedico más tiempo a los niños regulares" (D9) o "yo no estudié para eso, yo no me preparé para eso" (D5). Este tipo de discordancia en los planes de intervención lo convierten en una barrera en la inclusión educativa, considerando que en gran medida el aprendizaje de los estudiantes depende de lo que creen, pueden y están dispuestos a hacer los docentes y las expectativas que ellos mismos se trazan sobre sus alumnos (Sanini y Bosa, 2015). No se necesita que haya una construcción de modelos generalizados teniendo en cuenta que el ritmo de aprendizaje de cada niño es particular (Fundación Centros de Aprendizaje, 2010), pero sí que haya un interés por parte del docente de participar de forma positiva y proactiva en la enseñanza y creación de estrategias para el niño TEA.

De acuerdo a lo anterior, una de las estrategias más utilizadas y que se logró identificar en esta investigación es el acompañamiento permanente por parte del docente de apoyo, "el acompañamiento se puede contar como una estrategia" (D6) pero se refleja según los relatos de los participantes una notable carencia "se necesitan más docentes de apoyo" (D5), pues este apoyo juega un rol vital para los estudiantes (Coates, Lamb, Bartlett \& Datta, 2017). Debido a la concentración significativa de estudiantes con TEA en una misma institución, no hay la suficiente cobertura a nivel de acompañantes permanentes, es por esto, que como se mencionó anteriormente algunos de estos acompañamientos son brindados por los padres de familia de forma particular, otros estudiantes lo tienen por medio de tutelas a través de las EPS, o IPS (Instituciones Prestadoras De Salud) por medio de fundaciones se encargan de brindar el acompañante.

Cuando los docentes hacen referencia a que "se necesitan más docentes de apoyo" (D6), "acompañamiento permanente para potenciar habilidades y competencias (D3), "es fundamental que los estudiantes tengan un acompañamiento constante" (D8), están hablando de una necesidad o barrera que impide desarrollar adecuados procesos de inclusión, teniendo en cuenta que la inclusión es generar la misma igualdad de condiciones y oportunidades (Wilches, 2015) solo hay inclusión escolar si hay aprendizaje (Zapata, 2019) dicho aprendizaje esta mediado de los acompañantes. 


\section{Barreras en los procesos de Educación Inclusiva dirigidosa niños con Trastorno delEspectro Autista(TEA)}

Estudio cualitativo con docentes de una institución educativa

\section{¿Cómo superar las barreras asociadas a factores culturales y socioeconómicos?:}

Este tipo de barreras suelen ser muy complejas de superar teniendo en cuenta la cantidad de factores a las que están asociadas. Al abordar temas relacionados al factor económico los docentes manifiestan que "hay familiares que no tienen los recursos" (D4). Es de tener en cuenta las dificultades como el acceso al servicio médico, entre la cotidianidad que enfrentan las personas con TEA. El cálculo del coste económico anual para la sociedad supera los 136.000 millones de dólares sólo en Estados Unidos (Peacock, Amendah, Ouyang y Grosse, 2012; Cidav, Marcus y Mandell, 2012; Wang, Mandell, Lawer, Cidav y Leslie, 2013). Según la Academia Americana de Pediatría (AAP, 2020) 1 de cada 59 niños tiene un trastorno del espectro autista (TEA) en el mundo y según lo indica la APP el costo de por vida de la educación, la salud y otras necesidades de servicio para una persona con TEA oscila entre \$1.4 y \$2.4 millones de dólares, hecho que deja en evidencia que para una familia de bajos recursos se vuelve en ocasiones inmanejable satisfacer las necesidades del niño con TEA.

Por otra parte, en cuanto a las barreras socioculturales es indispensable que la sociedad sustituya conceptos, muchas personas entienden la discapacidad como una construcción cultural y los perciben como seres incompletos o como seres deficientes (Wilches, 2015). Este tipo de conceptos terminan afectando a las familias en su proceso de asimilación del diagnóstico "las familias en muchos casos no están preparadas para asumir la realidad de tener un niño especial" (D7), "hay un tema de duelo en la discapacidad" (D6) y el desafío está en reconocer el valor de la diversidad como un bien en sí mismo, que a su vez enriquece la sociedad; se debe eliminar esa visión problemática de las diferencias, en la cual el reconocimiento de dichas diferencias, vistas como amenazas, ha tenido como único propósito convertirlas en desigualdades (Ibid, 2015). El único propósito debe ser una participación igualitaria de todos los miembros de una sociedad en sus diferentes áreas: económica, legal, política, cultural, educativa, etc. (Gil, 2009).

El papel que juegan entes gubernamentales como el Ministerio de Educación, Secretaría de Educación, Ministerio de Salud y Secretaria de Salud (IPS y EPS), es otra de esas barreras que hace bastante presencia en las percepciones de los participantes según aseguran "un cuidador también debe recibir por parte de las EPS o las instituciones educativas una capacitación y una sensibilización del proceso, porque no es fácil" (D7) así mismo se garanticen acciones "el colegio y la secretaría de educación deberían sistematizar más la información de los procesos de aprendizaje con estos chicos" (D7), "lo más fácil es para el distrito es garantizar la ley, que todas las instituciones se acojan”(D6). Según el Decreto 1421, 2017 establecido por el Ministerio de Educación; es clave que los procesos terapéuticos trabajen de la mano con la escuela; estos trabajos interdisciplinares son fundamentales para garantizar una hegemonía con la educación inclusiva, "profesionales que atiendan con calidad y dignidad las necesidades de los niños" (C8) en procesos de fonoaudiología, psicología, terapia ocupacional, entre otros.

\section{Conclusiones}

Partiendo de dos parámetros fundamentales: la situación actual o con lo que cuentan las instituciones educativas y las oportunidades de mejora para llegar al éxito de la educación inclusiva, derivado de los resultados obtenidos se logra evidenciar en esta investigación, que se dan a conocer todas aquellas barreras que están limitando los procesos de educación inclusiva en la ciudad de Bogotá. Es fundamental llegar a un punto clave frente a cuáles son esas posibles soluciones o herramientas que mejoren de manera significativa estos procesos educativos de los niños con TEA. De acuerdo con la categoría central: Barreras que limitan la inclusión y según lo planteado en la Teoría Fundamentada por Corbin y Strauss (1998) donde, a partir de los datos obtenidos y donde se tiene en cuenta la situación actual de estas necesidades, es finalidad de esta investigación la estructuración de posibles opciones de mejora o estrategias como parte de la formulación de nueva teoría partiendo de los datos y lo identificado en las percepciones de los participantes, estas estrategias se presentan a continuación:

En primer lugar, los resultados de esta investigación apoyan la efectividad iniciativas y estrategias como el PIAR (Plan Individual de Ajustes Razonables) en los procesos de educación inclusiva y especialmente su implementación a partir del desarrollo de cartillas y planes de trabajos específicamente diseñados para atender las necesidades de los estudiantes con TEA. (Decreto 1420 de 2017).

En segundo lugar, resaltó la percepción de poco acompañamiento permanente y constante en los procesos educativos de los niños con TEA por parte de los docentes de apoyo, lo cual deriva en efectos negativos directos sobre la efectividad de los materiales y procesos pedagógicos dentro del aula. Es importante tomar en cuenta que el significado de inclusión educativa más allá de la mera asignación de un cupo escolar y de un espacio dentro del aula de clases, para verlo más cercano al ejercicio de la satisfacción de todas las necesidades que manifiesta el niño a nivel de aprendizaje, enseñanza, interacción social con el entorno educativo y en el desarrollo de metas individuales a nivel académico y personal.

En tercer lugar, se encuentra que es vital generar espacios de acompañamiento a estudiantes con TEA por medio de acuerdos y convenios entre universidades, hospitales y fundaciones de modo que se favorezca la articulación entre el sector salud y el educativo y con miras a que se pueda aumentar la participación de profesionales en formación o ya titulados en los procesos la formación del niño con TEA. En esta misma dirección, resulta de suma importancia que se establezcan canales de comunicación directa entre las instituciones educativas y las familias, de modo que las familias tengan un rol activo en los procesos de inclusión en la escuela y se fortalezca la comunicación bidireccional y el trabajo colaborativo en pro del avance de los estudiantes. Esta articulación también debe darse con los procesos terapéuticos, pues estos tienen una incidencia directa sobre los procesos educativos de los niños con TEA. No se puede lograr un avance significativo a nivel académico si paralelamente no se trabaja a nivel psicológico, motriz, lingüístico, etc.

Finalmente, el fortalecimiento de la formación para la diversidad en instituciones educativas debe ser también un eje fundamental y primordial para la optimización de los procesos de inclusión en toda la comunidad educativa. La realización de talleres, conversatorios, diplomados, jornadas pedagógicas, estudios de casos, mesas de dialogo, entre otras actividades que permitan y le brinden herramientas, estrategias, rutas y planes de acción al docente, resultan ser esenciales para la consecución una escuela más incluyente.

\section{Referencias}

Balcázar, P., González, A., López, N., Gurrola, G., Y Moysén, A. (2013). INVESTIGACIÓN CUALITATIVA. Universidad Autónoma del Estado de México. Recuperado de : file:///C:/Users/paola\%20garzon/Downloads/ Investigaci\%C3\%B3n\%20cualitativa.pdf 
Baña, M. (2015). El rol de la familia en la calidad de vida y la autodeterminación de las personas con trastorno del espectro del autismo. Ciencias psicológicas, 9 (2), 323336. Recuperado en 12 de octubre de 2017, de http://www.scielo.edu.uy/scielo.php?script=sci arttext\&pid=S1688-

Bareño, C. (2015) Inclusión educativa: fundamental para el tratamiento integral del trastorno del espectro autista (TEA). Revista: Universidad Nacional de Colombia.

Bejarano Gómez, A. (2020) A Inclusão Educacional e Digital da População com TEA na Colômbia. En: V. Caminha [et al.]. Autismo: Caminhos para a Inclusão. (pp. 95-119). Bogotá: Editorial ĬbërAM

Buescher, AV., Cidav, Z., Knapp, M. y Mandell, DS. (2014) Costs of autism spectrum disorders in the United Kingdom and the United States of America. JAMA Pediatr; 168: 721-8.

Calvo, G. (2009). Inclusión y Formación de Maestros. Revista Iberoamericana sobre Calidad, Eficacia y Cambio en Educación, 7(4), 78-94.

Casas, J., y Aparicio, L. (2016). Un análisis del autismo desde la perspectiva de su influencia en familias y la tecnología como facilitador en el manejo de esta condición. Revista Logos, Ciencia \& Tecnología, 8 (1). 168-182.

Catalano, D., Holloway, L. y Mpofu, E. (2018) Mental Health Interventions for Parent Carers of Children with Autistic Spectrum Disorder: Practice Guidelines from a Critical Interpretive Synthesis (CIS) Systematic Review. International Journal Environ Res Public Health 15(2): 341364.

Cidav, Z, Marcus, SC. y Mandell, DS. (2012) Implications of childhood autism for parental employment and earnings. Pediatrics 129: 617-23.

Coates, M., Lamb, J., Bartlett, B., \& Datta, P. (2017). Autism Spectrum Disorder Coursework for Teachers and Teacher-aides: An Investigation of Courses Offered in Queensland,Australia. Australian Journal of Teacher Education, 42(11)

Concejo de Bogotá (2019) Boletín Diario N. ${ }^{\circ} 641$ martes 02 de abril de 2019. Recuperado de:http://concejodebogota.gov.co/boletin-diario-n-641martes-02-de-abril-de-2019/cbogota/2019-04-02/161939.php

Cuxart, F. (2000). El Autismo, aspectos descriptivos y terapéuticos. Málaga, España: Ediciones Aljibe.

Creswell, J. (1999/2007). Research Design Choosing Among Five Approaches. E.U. SAGE Publications.

Denzin, N., y Lincoln, Y. (2012). Manual de investigación cualitativa. El campo de la investigación cualitativa. Vol. 1. Barcelona: Gedisa.

Decreto 1421 (2017), Ministerio de Educación Nacional.

Decreto 366 (2009), Ministerio de Educación Nacional.

De la Cuesta, C. (2006). La teoría fundamentada como herramienta de análisis. Cultura de los cuidados, 20, pp. 136-140. Recuperado de: http://hdl.handle.net/10045/876

De Goñi, A. (2015). La familia del niño con trastorno del espectro autista: de la detección a la aceptación (Trabajo de grado). Universidad de Navarra. Madrid, España.

Diazgranados, J. y Tebar, M. (2018). Estado del arte sobre las orientaciones y lineamientos pedagógicos para el trabajo educativo de personas con espectro autista en Colombia durante los últimos diez años. Corporación Universitaria Iberoamericana, Facultad de Educación.

Echeita, G. (2008). Inclusión y exclusión educativa. "Voz y quebranto". REICE - Revista Electrónica Iberoamericana sobre Calidad, Eficacia y Cambio en Educación 2008, 6 (2), 9- 18.

Escribano, A., Y Martínez, A. (2013). Inclusión educativa y profesorado inclusivo.Recuperado de: https://books.google.com.co/ books?id=78i2cjCiNooC \&printsec=frontcover\&hl=es\#v=onepage \&q\&f=false

Flick, U. (2007). Introducción a la investigación cualitativa. Segunda edición. Madrid: Ediciones Morata, S. L.
Freixa, M. (1993). Familia y Deficiencia mental. Salamanca: Amarú.

Fundación centros de Aprendizaje (2010), Orientaciones pedagógicas para la inclusión de estudiantes en situación de discapacidad.

Gallimore, R., Weisner, T.S., Kaufman, S.Z., \& Bernheimer, L.P (1989). The social construccion of ecocultural niches: Family accomodation of developmentally delayed children. American Journal on Mental Retardation, 94(3), 216-230.

Harris, S. L. (2001). Los hermanos de niños con autismo. Su rol específico en las relaciones familiares. Madrid: Narcea.

Hernández, R., Fernández, C., y Baptista, P. (2014). Metodología de la investigación. Sexta edición. México: McGRAW-HILL/ INTERAMERICANA EDITORES, A.A. DE C.V.

Hernández, R., Fernández C., y Baptista, M. (2010). Metodología de la Investigación.México. Mc Graw Hill. Quinta Edición.

Información general sobre autismo. (22 de diciembre de 2015). Obtenido de sitio Web Autism Society: http://www.autism-society.org/enespanol/

Ley Estatutaria 1618 (2013), Congreso de la República de Colombia.

Ley General de Educación 115 (1994), Congreso de la República de Colombia.

Ley 1145 (2007), Congreso de la República de Colombia.

Massani, J., García, X., y Hernández, E. (2015). La evaluación psicopedagógica de niños (as) con trastornos del espectro autista mediante el perfil psicoeducativo. Revista Universidad y Sociedad, 1 (2), 145-151.

Marco, C.L.S.T. (2011). O aluno com síndrome de asperger em sala de aula. Temas sobre Desenvolvimento, 18 (102), 63-65.

Ministerio de Educación Nacional. (2017). Documento de orientaciones técnicas, administrativas y pedagógicas para la atención educativa a estudiantes con discapacidad en el marco de la educación inclusiva. Recuperado de: file:///C:/Users/psicologiaeducativa/Desktop/ PSICOLOG\%C3\%8DA\%20EDUCATIVA/PSicolog\%C3\%ADa\%202019I/ tesis\%202019/Documento\%20de\%20orientaciones\%20tecnicas, \%20 administrativas $\% 20$ \%20pedagogicas $\% 20$ para\%20la\%20atencion $\% 20$ educativa\%20a\%20estudiantes\%20con\%20discapacidad\%20en\%20 el\%20marco\%20de\%20la\%20educacion\%20inclusiva.pdf

Ministerio de Salud y Protección Social. (2017). Protocolo Clínico para el Diagnóstico, Tratamiento y Ruta de Atención Integral de Niños y Niñas con Trastorno del Espectro Autista. Ministerio de Salud y Protección Social. Instituto de Evaluación Tecnológica en Salud. Colombia. Bogotá.

Milla, M., y Mulas, F. (2009). Atención temprana y programas de intervención específica en el trastorno del espectro autista. REV NEUROL, 48 (Supl 2). S47-S52.

Molano, G. y Bejarano-Gómez, A. (2017). La inclusión desde la institución educativa. En: Y. Rodríguez Hernández [et al.]. Diversidad e inclusión: reconocer lo que hacemos Vol. I (pp. 127-186) Bogotá. Editorial IbërAM

Navarrete, J. (2004). Sobre la investigación cualitativa. Nuevos conceptos y campos de desarrollo. Investigaciones Sociales, 8 (13), 277-299.

Nunes, D., \& Schmidt, C. (2019). Special education and autism: from evidence-based practices to school. Cadernos de Pesquisa, 49(173), 84-103. Epub October 17, 2019.https://doi.org/10.1590/198053145494

OMS. (2019). Organización Mundial de la Salud. Recuperado de : https:// www.who.int/es/news-room/fact-sheets/detail/autism-spectrumdisorders

Orrú, S. (2010). Contribuciones del abordaje histórico-cultural a la educación de alumnos autistas. Humanidades Médicas, 10(3), 1-11. Recuperado en 06 de marzo de 2020, de http://scielo.sld.cu/scielo.php?script=sci arttext\&pid=S1727$81202010000300002 \&$ lng=es\&tling=es.

Peacock, G., Amendah, D., Ouyang, L. y Grosse, SG. (2012) Autism spectrum disorders and health care expenditures: the effects of co-occurring conditions. J Dev Behav Pediatr 33: 2-8. 


\section{Barreras en los procesos de Educación Inclusiva dirigidos a niños con Trastorno del Espectro Autista (TEA)}

Estudio cualitativo con docentes de una institución educativa

Perrin, B., \& Nirje, B. (1985). Setting the record straight: a critique of some frequent misconceptions of the normalization principle. Australia and New Zealand Journal of Developmental Disabilities, 11(2), 69-74.

Proyecto de ley 046 (2017), Congreso de la República de Colombia.

Proyecto de ley 083 (2015), Congreso de la República de Colombia.

Sanini, C., y Bosa, C. (2015). Autismo e inclusão na educação infantil: Crenças e autoeficácia da educadora. Estudos de Psicologia (Natal), 20(3), 173-183. https://doi.org/10.5935/1678-4669.20150019

Strauss, A., y Corbin, J. (1998/2002). Bases de la investigación cualitativa. Técnicas y procedimientos para desarrollar la teoría fundamentada. Editorial Universidad de Antioquia.

Tomkiewicz, S. (1979). Relación del débil mental con su familia. Siglo Cero, $66,12-29$.
Vargas, M., y Navas, W. (2012). Autismo Infantil. Revista Cúpula, 26 (2). 44-58.

Wang, L., Mandell DS., Lawer, L., Cidav, Z. y Leslie, DL. (2013) Healthcare service use and costs for autism spectrum disorder: a comparison between Medicaid and private insurance. Journal of Autism Development Disorder, 43: 1057-64.

Wilches; K. (2015). Inclusión social y educativa del trastorno espectro autista (TEA) (Trabajo de grado). Universidad Nacional Abierta y a Distancia UNAD, Tunja, Colombia.

Zapata, L. (2019). El profesor que enseña matemáticas en la inclusión escolar de niños con Trastorno de Espectro Autista (TEA). En Conferencia Interamericana de Matemática. Conferencia llevada a cabo en XV CIAEM-IACME, Medellín, Colombia.

\section{Anexos}

\section{Anexo 1.}

\section{Protocolo \# 1 de instrumentos para recolección de datos.}

\section{Preguntas orientadoras:}

Desde su experiencia profesional ¿cómo caracterizaría los TEA?

Desde su experiencia profesional ¿Cómo se manifiestan las dificultades en las habilidades sociales y la comunicación, en el contexto del aula de clase?

3. Sabemos que hoy día se habla del autismo en términos de un espectro, dada la variedad en que puede manifestarse esta condición. Teniendo en cuesta esto ¿cómo se planean y desarrollan las estrategias pedagógicas en el aula de clase?

4. ¿De qué manera se garantiza el cumplimiento de los objetivos señalados en el currículo institucional, teniendo en cuenta la variedad ya señalada de este trastorno?

5. Desde su experiencia profesional y personal ¿cuál es su percepción acerca de cómo se desarrollan los procesos de inclusión de los niños con TEA?

6. Teniendo en cuenta esta caracterización ¿Cuál sería el rol o el papel que desempeñan los docentes con relación a la inclusión de niños con TEA

¿Qué tipo de herramientas proporciona la institución educativa para facilitar el proceso de inclusión de los niños con TEA?

8. ¿De qué manera afectan las dinámicas de otras instituciones no educativas (p.e. gubernamentales, de salud, etc.) en los procesos de educación inclusiva de la población TEA?

9. ¿Cuáles son las barreras que ha identificado que dificultan el proceso de educación inclusiva del niño con TEA a nivel de ingreso?

10. ¿Cuáles son las barreras que ha identificado que dificultan el proceso de educación inclusiva del niño con TEA a nivel de permanencia?

11. ¿Cuáles factores identificaría como generadores de exclusión que afectan a la población con TEA?

12. ¿Qué aspectos considera necesario fortalecer para facilitar el desarrollo de los procesos de inclusión en la institución? 


\section{Anexo 2.}

Protocolo \# 2 de instrumentos para recolección de datos.

Preguntas orientadoras:

\section{Necesidad de acompañamiento permanente de docentes}

Teniendo en cuenta que las necesidades de un niño con TEA son diferentes a las de un niño regular ¿de qué manera impacta el acompañamiento constante dentro del aula en el proceso educativo de un niño con TEA?

Desde su experiencia profesional ¿Cómo debe ser el proceso de acompañamiento dentro del aula para niños con TEA?

\section{Necesidad de fortalecer procesos de Psicoeducación sobre el TEA}

¿Qué tipo de capacitaciones/formaciones le ha brindado la institución sobre la educación inclusiva?

¿Qué tipo de información y/o capacitación considera necesarios brindar por parte de la Institución educativa para garantizar un adecuado proceso educativo de los niños con TEA?

Desde su percepción ¿cómo se podría implementar la psicoeducación del TEA en niños regulares y comunidad en general?

\section{Plan curricular y estrategias pedagógicas centradas en las características de los estudiantes}

Teniendo en cuenta que el proceso de evaluación se diferencia de acuerdo a las competencias de cada niño con TEA, ¿Cómo se evalúan los avances o falencias dentro del proceso educativo de cada niño con TEA?

¿Qué estrategias se podrían implementar para mitigar la carencia de docentes de apoyo dentro de las aulas?

\section{Rol del docente}

Desde su rol como docente, ¿qué herramientas ha implementado en el aula de clase para garantizar la inclusión en un niño con TEA?

Desde su rol como docente y según su experiencia profesional ¿Qué estrategias aparte de las existentes se pueden implementar para garantizar el aprendizaje de los niños con TEA Concepciones sobre los procesos desarrollados en la institución

Dentro del marco de la educación inclusiva ¿Cómo se garantizan los procesos de socialización - interacción de niños regulares con niños TEA, dentro y fuera de las aulas de clase?

Importancia de considerar la variabilidad del trastorno para ajuste curricular y pedagógico

¿Cómo percibe el impacto en un niño TEA estar dentro de un aula donde los procesos de formación son diferentes en relación a los niños regulares?

\section{Barreras que limitan la inclusión}

Desde su experiencia profesional ¿Qué impacto genera en los procesos educativos de un niño TEA la cantidad significativa de estudiantes en un mismo salón?

\section{Dificultades presentes en el trastorno asociadas a pautas de crianza}

En una fase de recolección anterior identificamos en los relatos de docentes, que la dificultad en el afrontamiento del TEA por parte de cuidadores generaba unas implicaciones frente a los procesos educativos de los niños TEA ¿qué tipo de implicaciones considera usted que esto genera y por qué?

Importancia de la participación de cuidadores para el éxito de los procesos educativos

Desde su experiencia como docente, ¿cómo considera debería ser la participación de los cuidadores en los procesos educativos del menor con TEA? 


\section{Anexo 3.}

\section{Protocolo \# 3 de instrumentos para recolección de datos.}

\section{Grupo focal}

\section{Preguntas orientadoras:}

$\rightarrow$ Estrategias inclusivas implementadas en la institución (Ajustes curriculares y pedagógicos que consideren la variabilidad del TEA Con base en la experiencia y trabajo con pares): TEA:

Previo a datos anteriores se llegó a la consolidación de la categoría de estrategias utilizadas en los procesos de educación inclusiva en niños

$\rightarrow$ ¿Cuáles consideran son las estrategias con mayor viabilidad para trabajar en el aula con los niños TEA?

$\rightarrow$ ¿Desde su percepción cree que el Trabajo con pares (procesos de imitación), sensibilización de niños regulares y socialización dentro del contexto educativo son favorables para los procesos educativos de los niños con TEA?

\section{Barreras que limitan la inclusión: Aula: cantidad, calidad, proceso de evaluación.}

$\rightarrow$ Se ha encontrado que la cantidad significativa de estudiantes en un salón afectan los procesos educativos del niño TEA, incluso del niño regular ¿Concreta y específicamente en qué aspectos se ve afectado el niño TEA?

\section{Formación: Conocimiento, formación, sensibilización:}

$\rightarrow$ ¿cómo afecta los procesos educativos del niño con autismo la falta de conocimiento y

$\rightarrow$ formación sobre el manejo en los procesos de educación inclusiva del TEA en docentes titulares?

\section{Rol de entes gubernamentales: Eps, secretaria de educación}

$\rightarrow$ Desde su percepción como docente ¿de qué manera afecta en los procesos educativos del niño TEA, la falta de apoyo por parte de entes gubernamentales?

$\rightarrow$ Acompañamiento constante y profesional: acompañamiento permanente por parte de un profesional.

$\rightarrow$ iporque el proceso de acompañamiento debe ser permanente y por un profesional?

\section{Familiar: procesos de afrontamiento frente al diagnóstico, rol del cuidador}

$\rightarrow$ ¿Cómo se debe garantizar el apoyo a los cuidadores frente al afrontamiento del diagnóstico?

$\rightarrow$ Bajo la aparente carencia del rol activo del cuidador del niño TEA en los procesos educativos ¿Cómo se debe garantizar esa participación por parte de los cuidadores?

\section{Socioeconómico: recursos económicos}

$\rightarrow$ ¿Porque se debe tener en cuenta el factor socioeconómico como barrera que limita la inclusión?

\section{Cultural: creencias, costumbres}

$\rightarrow$ ¿A nivel cultural cuáles son esas barreras que limitan la inclusión de los niños TEA? 